\title{
Pengaruh Penggunaaan Pemancar-penerima pada Controller Area Network
}

\author{
R. Mochammad A. B. Satria, Awang N. I. Wardana*, dan Nazrul Effendy \\ Departemen Teknik Nuklir dan Teknik Fisika, Fakultas Teknik, Universitas Gadjah Mada \\ Yogyakarta, Daerah Istimewa Yogyakarta, Indonesia \\ *Corresponding author, e-mail: awang.wardana@ugm.ac.id
}

\begin{abstract}
Abstrak- Controller Area Network (CAN) merupakan suatu protokol jaringan komunikasi yang telah digunakan pada berbagai bidang seperti sistem kendaran bermotor sampai sistem industri proses. Modul masukan/keluaran sebagai node dalam jaringan CAN dapat terletak berdekatan dengan pengendali atau jauh dari pengendali. Di sisi lain, jaringan CAN harus memiliki sistem pengkabelan yang sederhana dan waktu latensi yang singkat. Jaringan komunikasi CAN dapat dibangun dengan menggunakan pemancarpenerima dan tanpa pemancar-penerima. Analisis performa dari kedua jaringan tersebut dilakukan untuk mengetahui pada panjang kabel berapa komponen pemancar-penerima dibutuhkan. Dalam penelitian ini, dilakukan analisis dari pengaruh komponen pemancar-penerima terhadap parameter latensi, dalam panjang kabel yang bervariasi. Terdapat dua faktor dalam melakukan analisis data, yaitu faktor komponen pemancar-penerima dan faktor variasi panjang kabel pada $50 \mathrm{~m}, 55 \mathrm{~m}, 60 \mathrm{~m}, 65 \mathrm{~m}$, dan $70 \mathrm{~m}$. Metode yang diimplementasikan dalam melakukan analisis data adalah uji analisis variasi dua jalur dan uji kontras Tukey, dengan tingkat signifikansi sebesar 0,05 . Uji analisis variasi dua jalur memberikan tiga hasil nilaip dari pengaruh pemancar-penerima, pengaruh variasi panjang kabel, serta interaksi dari keduanya, yaitu berturut-turut sebesar 0,0003, 0,0008, dan 0,0034. Hasil tersebut lebih kecil dari tingkat signifikansi yang digunakan, sehingga dapat ditarik kesimpulan bahwa komponen pemancar-penerima serta variasi panjang kabel mempengaruhi nilai latensi sistem secara signifikan. Hasil uji Tukey juga menunjukan bahwa selama panjang kabel kurang dari $65 \mathrm{~m}$, latensi dari jaringan CAN tanpa pemancar-penerima tidak berbeda secara signifikan. Hasil analisis tersebut menunjukan bahwa bahwa jaringan CAN tanpa pemancar-penerima dapat digunakan dengan baik selama panjang kabel kurang dari $65 \mathrm{~m}$.
\end{abstract}

Kata kunci : CAN, protokol komunikasi, variasi panjang kabel, latensi

\begin{abstract}
Controller Area Network (CAN) is a communication network protocol that has been used in various fields as in automotive system to the industrial process. Input/output module as the CAN node in the network can be located nearby or distant from the controller. On the other hand, the CAN network must be designed to reduce the wiring harness significantly with latency as short as possible. CAN protocol can be built with and without the transceiver component. Analysis of the performance of both types of CAN network is conducted to know the exact distance to use transceiver. This research was conducted to analyze the impact of the transceiver on the latency of the CAN system, within the bus length variation. The transceiver and cable length variation were used as the factors of the statistical test that was conducted as the data analysis method in the research. The bus length varies from $50 \mathrm{~m}, 55 \mathrm{~m}, 60 \mathrm{~m}, 65 \mathrm{~m}$, to $70 \mathrm{~m}$. The two-way analysis of variance test and Tukey contrast test were used with a significance level of 0.05 . There are three results of the two-way analysis of variance test, showing that significant differences have occurred on the effect of the transceiver, the bus length variation, and interaction between them, giving a p-value of $0.0003,0.0008$, and 0.0034 respectively. The results of the Tukey contrast test have shown that the latency of CAN systems without transceiver does not differ significantly on less than $65 \mathrm{~m}$ cable length. The analysis has concluded that the CAN system can well function without transceiver which is the cable length is less than $65 \mathrm{~m}$.
\end{abstract}

Keywords : CAN, communication protocol, cable length variation, latency

\section{Pendahuluan}

Sistem elektronik dari suatu kendaraan bermotor, khususnya pada mobil, tersusun dari sejumlah electronic control units (ECU) [1] yang memiliki berbagai macam fungsi kontrol. Dalam kendaraan bermotor, pada umumnya diinginkan suatu sistem yang tingkat keamanan dan kenyamanannya lebih baik, dan juga konsumsi 
bahan bakar yang lebih sedikit. Kendaraankendaraan pada jaman modern memiliki banyak ECU untuk berbagai macam subsistem, seperti airbags, antilock braking system, kontrol mesin, sistem audio, jendela, pintu, pengaturan cermin pada spion, dan sebagainya [1]. Agar sistem dalam kendaraan dapat bekerja, dibutuhkan komunikasi yang baik antara subsistem-subsistem yang ada dalam kendaraan tersebut. Namun demikian, terdapat beberapa masalah yang sering muncul [1], yaitu sistem pengkabelan yang terlalu kompleks, keterbatasan ruangan, dan masalah-masalah kehandalan. Dengan demikian, sebagai solusi dari permasalahan tersebut, maka diciptakanlah teknologi jaringan dalam suatu kendaraan.

\subsection{Controller Area Network (CAN)}

Protokol-protokol jaringan yang ada dalam suatu kendaraan harus memenuhi kebutuhankebutuhan yang ada, termasuk penyederhanaan sistem pengkabelan secara signifikan, mengurangi beban pada body kendaraan, waktu latensi yang singkat, dan juga fleksibilitas dalam melakukan konfigurasi [2]. Dalam menjalankan fungsinya, tiap-tiap ECU harus dapat berkomunikasi dalam nilai latensi yang ditentukan. Sehingga, untuk memenuhi kebutuhan tersebut, digunakanlah protokol komunikasi controller area network (CAN).

Sebelum ditemukannya protokol komunikasi CAN, digunakan protokol komunikasi domestic digital bus (D2B) yang menggunakan topologi jenis ring [1]. D2B memiliki kerugian dalam hal kehandalan, dimana ketika terjadi kegagalan pada suatu node, maka seluruh sistem akan gagal.

Protocol komunikasi CAN adalah protokol komunikasi yang menggunakan sistem multimaster yang dikembangkan oleh Robert Bosch. Antar muka protocol komunikasi CAN mempunyai kecepatan maksimal data dikirim melalui komunikasi serial sebesar $1 \mathrm{Mbps}$ [3].

Pada sistem otomotif sebelum memanfaatkan CAN, antar ECU dihubungkan dalam topologi mesh [1], sehingga dibutuhkan banyak kabel untuk menghubungkan ECU dalam jumlah banyak. Dengan menggunakan protokol komunikasi CAN, antar ECU akan terhubung dalam topologi bus, yang memiliki keuntungan berupa kecepatan transmisi data yang tinggi, jumlah kabel yang lebih sedikit, juga tingkat kehandalan yang lebih tinggi karena user dapat menambah dan menghilangkan suatu node sesuai dengan kebutuhan [4].

Implementasi dengan menggunakan CAN memiliki sistem pengkabelan yang sederhana karena hanya menggunakan dua kabel untuk menghubungkan dua node. Waktu latensi CAN juga cukup singkat [3]. Implementasi jaringan yang menggunakan protocol komunikasi CAN dapat dibangun dengan menggunakan pemancarpenerima (transciever) dan tanpa pemancarpenerima [5][6].

\subsection{Tujuan Penelitian}

Analisis performa dari kedua jaringan tersebut dilakukan untuk mengetahui pada panjang kabel berapa komponen pemancar-penerima dibutuhkan. Dalam penelitian ini, analisis pengaruh komponen pemancar-penerima terhadap parameter latensi dilakukan dalam panjang kabel yang bervariasi pada suatu sistem yang menggunakan jaringan protokol komunikasi CAN.

\section{Metodologi}

\subsection{Pemodelan Panjang Kabel}

Pemodelan panjang kabel ini dilakukan dengan melakukan perhitungan matematis untuk mendapatkan nilai resistansi, induktansi, dan kapasitansi dari panjang kabel yang dibutuhkan. Rangkaian pemodelan kabel digunakan untuk memodelkan panjang kabel $50 \mathrm{~m}, 55 \mathrm{~m}, 60 \mathrm{~m}, 65$ $\mathrm{m}$, dan $70 \mathrm{~m}$. Nilai hasil perhitungan kemudian diterapkan dalam rangkaian listrik menggunakan komponen resistor (R), induktor (L), dan kapasitor (C). Hasil pemodelan panjang kabel ini akan digunakan dalam proses implementasi serta pengambilan dan analisis data.

\subsection{Implementasi Jaringan CAN}

Implementasi jaringan CAN dilakukan dengan membuat program yang menjalankan fungsi komunikasi data dalam skenario kontrol antara node berupa Programmable System on Chip (PSoC) 3 CY8CKIT-030 [7]. Variasi panjang kabel $50 \mathrm{~m}$, $55 \mathrm{~m}, 60 \mathrm{~m}, 65 \mathrm{~m}$, dan $70 \mathrm{~m}$ diterapkan pada jaringan CAN melalui pemodelan dalam rangkaian R-L-C. Pemodelan kabel dalam proses implementasi akan memberikan variasi nilai jarak yang memisahkan antar node. Pengaruh pada parameter latensi kemudian dapat dianalisis, dan dievaluasi untuk mengetahui jenis jaringan mana yang lebih baik. Program uji yang digunakan pada tahapan implementasi ini ditanamkan pada PSoC [7]. Faktor pemancar-penerima dan variasi panjang kabel sebagai variabel independen dan parameter latensi sebagai variabel dependen 


\subsection{Pengambilan dan Analisis Data}

Pengambilan data dilakukan dengan menggunakan Osiloskop Hantek DSO5072P [8]. Dalam pengambilan data ini, terdapat dua hal yang diamati, yaitu ketika perangkat masukan pada node pemancar menerima masukan dan perangkat keluaran pada node penerima bekerja. Pada osiloskop digunakan dua kanal pengukuran, yang berfungsi untuk mengamati sinyal perangkat masukan di kanal pertama dan sinyal perangkat masukan di kanal kedua. Nilai parameter latensi diperoleh dari selisih waktu antara sinyal saat perangkat masukan mulai menerima masukan dan saat perangkat keluaran mulai bekerja. Pengambilan data latensi dilakukan pada tiap jenis jaringan baik itu dengan pemancar-penerima maupun tanpa pemancar-penerima, yang dilakukan pada tiap-tiap variasi panjang kabel $50 \mathrm{~m}, 55 \mathrm{~m}, 60$ $\mathrm{m}, 65 \mathrm{~m}$, dan $70 \mathrm{~m}$, masing-masing sebanyak lima kali pengukuran, sehingga total data latensi yang diambil sebanyak 50 data.

Analisis data dilakukan dengan melakukan pengujian statistik, yang memiliki hipotesis awal $\left(\mathrm{H}_{\mathrm{o}}\right)$ dan hipotesis alternatif $\left(\mathrm{H}_{1}\right) . \mathrm{H}_{\mathrm{o}}$ menyatakan bahwa perbedaan faktor, baik itu faktor dengan/tanpa pemancar-penerima, faktor variasi panjang kabel, serta hubungan antara keduanya, akan memberikan nilai parameter latensi yang sama $\mathrm{H}_{1}$ menyatakan bahwa perbedaan faktor akan memberikan nilai parameter latensi yang berbeda signifikan.

Uji statistik dilakukan dengan menggunakan uji analisis variansi dua arah, dimana jenis jaringan dengan/tanpa pemancar-penerima, variasi panjang kabel sebagai faktor independent sedangkan satu faktor variabel dependen yaitu parameter latensi. Pengukuran parameter latensi dilakukan secara berulang. Uji Tukey dilakukan saat didapatkan penolakan $\mathrm{H}_{\mathrm{o}}$ dan penerimaan $\mathrm{H}_{1}$ dari uji analisis variansi. Uji Tukey dilakukan untuk mendapatkan informasi mengenai pada nilai panjang kabel berapa nilai parameter latensi dari kedua jaringan CAN berbeda secara signifikan. Pengujian statistik pada penelitian ini dilakukan dengan perangkat lunak statistik R [9].

\section{Hasil dan Pembahasan}

\subsection{Implementasi Pemodelan Panjang Kabel}

Untuk melakukan pemodelan, maka harus diketahui dulu karakteristik material dan geometri dari kabel yang digunakan. Kabel yang dimodelkan dalam penelitian ini adalah kabel jenis Unshielded
Twisted-Pair (UTP) berstandar American Wiring Gauge (AWG) 20, dengan konduktor berbahan tembaga dan insulator berbahan polietilen dengan densitas tinggi [10], yang memiliki nilai resistivitas ( $\rho)$ sebesar 1,7 x 10-8 $\Omega \mathrm{m}$ [11], konstanta dielektrik $\left(\varepsilon_{r}\right)$ sebesar 2,4 [11], jari-jari penampang (r) sebesar 0,0405 $\mathrm{cm}$ [12], dan jarak separasi antara kabel (D) sebesar 0,2159 cm. Nilai-nilai karakteristik material dan geometri dari kabel yang dimodelkan dapat direpresentasikan pada Tabel 1.

Tabel 1. Karakteristik material dan geometri kabel

\begin{tabular}{ccc}
\hline No & Variabel & Keterangan \\
\hline 1. & Jenis Kabel & UTP \\
2. & Standar & AWG20 \\
3. & Konduktor & Tembaga \\
4. & Insulator & HDPE \\
5. & Resistivitas Konduktor $(\rho)$ & $1,7 \times 10^{-8} \Omega \mathrm{m}$ \\
6. & Permitivitas Insulator $(\varepsilon r)$ & 2,4 \\
7. & Jari-jari Penampang $(r)$ & $0,0405 \mathrm{~cm}$ \\
8. & Jarak Separasi Kabel $(D)$ & $0,2159 \mathrm{~cm}$ \\
\hline
\end{tabular}

Dengan memasukan nilai dari parameter geometri serta karakteristik material ke dalam persamaan perhitungan resistansi $(R)$, induktansi $(L)$, dan kapasitansi $(C)$ untuk pemodelan [13] tersebut, maka didapatkan nilai resistansi, induktansi, dan kapasitansi per satuan panjang melalui persamaan (1) sampai persamaan (3).

$$
\begin{aligned}
\frac{R}{l} & =\frac{\rho}{\pi r^{2}} \\
C_{a b} & =\frac{\pi \varepsilon_{r}}{4 \pi \cdot 9 \cdot 10^{9} \ln \left(\frac{D}{r}\right)} \\
L_{a+b} & =4 \times 10^{-7}\left[\ln \left(\frac{D}{r}\right)\right]
\end{aligned}
$$

Dengan memasukan nilai variable sesuai pada Tabel 1 maka akan didapatakan $\frac{R}{l}=0,033 \frac{\Omega}{m}, C_{a b}=$ $39,84 \frac{p F}{m}, L_{a+b}=0,6694 \frac{\mu H}{m}$.

Tabel 2. Nilai R-L-C yang dibutuhkan dalam pemodelan

\begin{tabular}{cccc}
\hline $\begin{array}{c}\text { Panjang } \\
\text { kabel }(\mathrm{m})\end{array}$ & $\begin{array}{c}\text { Resistansi } \\
(\Omega)\end{array}$ & $\begin{array}{c}\text { Induktansi } \\
(\mu \mathrm{H})\end{array}$ & $\begin{array}{c}\text { Kapasitansi } \\
(\mathrm{pF})\end{array}$ \\
\hline 1 & 0,033 & 0,6694 & 39,840 \\
50 & 1,650 & 33,470 & 1992,0 \\
55 & 1,815 & 36,817 & 2191,2 \\
60 & 1,980 & 40,164 & 2390,4 \\
65 & 2,145 & 43,511 & 2589,6 \\
70 & 2,310 & 46,858 & 2788,8 \\
\hline
\end{tabular}


Kabel yang dimodelkan memiliki panjang sebesar $50 \mathrm{~m}, 55 \mathrm{~m}, 60 \mathrm{~m}, 65 \mathrm{~m}$, dan $70 \mathrm{~m}$. Nilai parameter R-L-C untuk tiap pemodelan kabel yang dibutuhkan dalam penelitian ini dapat direpresentasikan pada Tabel 2.

Nilai parameter resistansi, induktansi, dan kapasitansi yang telah didapatkan kemudian diterapkan pada kabel dalam suatu rangkaian pemodelan R-L-C (Gambar 1).

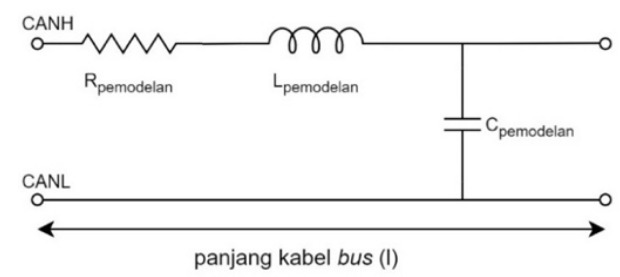

Gambar 1. Skema rangkaian pemodelan pada kabel CAN

Setelah melakukan pembuatan rangkaian pemodelan panjang kabel, maka dilakukan verifikasi terhadap pemodelan tersebut. Verifikasi model dilakukan pada rangkaian pemodelan kabel sepanjang $70 \mathrm{~m}$, yang diterapkan pada jaringan CAN tanpa pemancar-penerima. Rangkaian verifikasi pemodelan dapat digambarkan pada Gambar 2.

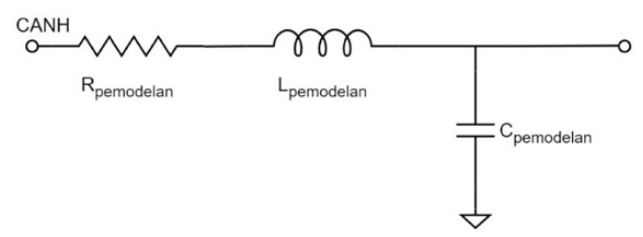

Gambar 2. Rangkaian verifikasi pemodelan

Rangkaian jaringan CAN riil diterapkan dengan menggunakan kabel sepanjang $70 \mathrm{~m}$ yang dipartisi menjadi 14 bagian, sehingga didapatkan tiap bagiannya sepanjang $5 \mathrm{~m}$. Tiap bagian sepanjang 5 $\mathrm{m}$ tersebut kemudian dijadikan gulungan-gulungan kabel agar lebih efisien. Dengan menggunakan perangkat osiloskop, pada proses pengamatan sinyal didapatkan bahwa rangkaian jaringan CAN sepanjang $70 \mathrm{~m}$ tidak dapat menjalankan fungsi komunikasi. Hal yang serupa juga didapatkan pada rangkaian pemodelan kabel sepanjang $70 \mathrm{~m}$ untuk jaringan CAN tanpa pemancar-penerima. Dengan demikian, didapatkan kesamaan bahwa pada rangkaian pemodelan $70 \mathrm{~m}$ serta rangkaian jaringan CAN sepanjang $70 \mathrm{~m}$, keduanya tidak dapat menjalankan fungsi komunikasi. Bentuk sinyal tegangan jaringan CAN pada rangkaian pemodelan serta rangkaian riil $70 \mathrm{~m}$ dapat direpresentasikan pada Gambar 3.

Dengan melakukan pengamatan sinyal tegangan jaringan CAN kedua rangkaian riil dan pemodelan, maka didapatkan persamaan bentuk sinyal, yaitu terdapat derau pada saat kondisi sinyal resesif. Derau yang terjadi pada rangkaian riil menjadi lebih banyak dan besar karena digunakannya 14 gulungan kabel masing-masing sepanjang $5 \mathrm{~m}$, yang saling dihubungkan menjadi $70 \mathrm{~m}$. Derau tersebut terjadi karena ada beberapa koneksi tambahan karena bertambahnya panjang kabel. Pada rangkaian riil, saat bit dominan didapatkan nilai tegangan berubah sebesar $4 \mathrm{~V}$ terhadap bit resesif, sedangkan pada rangkaian pemodelan, tegangan pada bit dominan adalah sebesar $3.2 \mathrm{~V}$. Dengan demikian, maka didapatkan kesalahan pemodelan terhadap keadaan riil sebesar 0,2. Dengan demikian, maka didapatkan hasil bahwa sinyal tegangan jaringan CAN pada rangkaian pemodelan menyerupai sinyal tegangan pada rangkaian riil $70 \mathrm{~m}$, sehingga dapat dikatakan pemodelan telah terverifikasi.

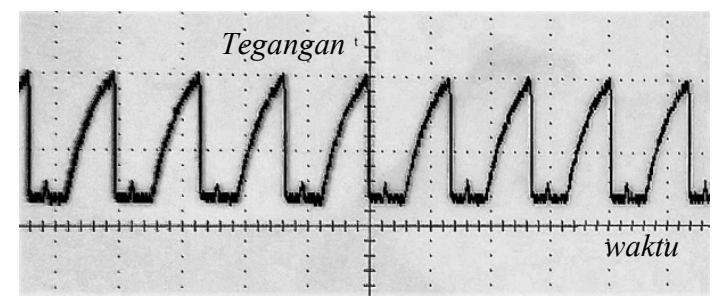

(a)

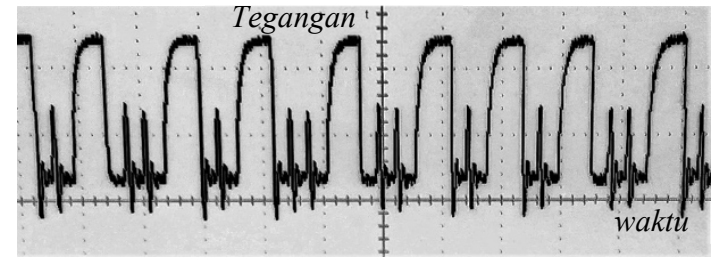

(b)

Gambar 3. Sinyal tegangan pada jaringan CAN (a) rangkaian pemodelan dan (b) rangkaian riil pada panjang kabel $70 \mathrm{~m}$ dengan(Tegangan/Div $=2 \mathrm{~V}$ dan waktu/Div $=20 \mu \mathrm{s})$

\subsection{Implementasi pada Sistem Jaringan CAN}

Implementasi sistem jaringan komunikasi berbasis CAN dilakukan untuk dua node berupa perangkat keras $\mathrm{PSoC}$. yang telah tertanam komponen pengendali $\mathrm{CAN}$, sehingga tidak dibutuhkan lagi komponen pengendali CAN eksternal [7]. 


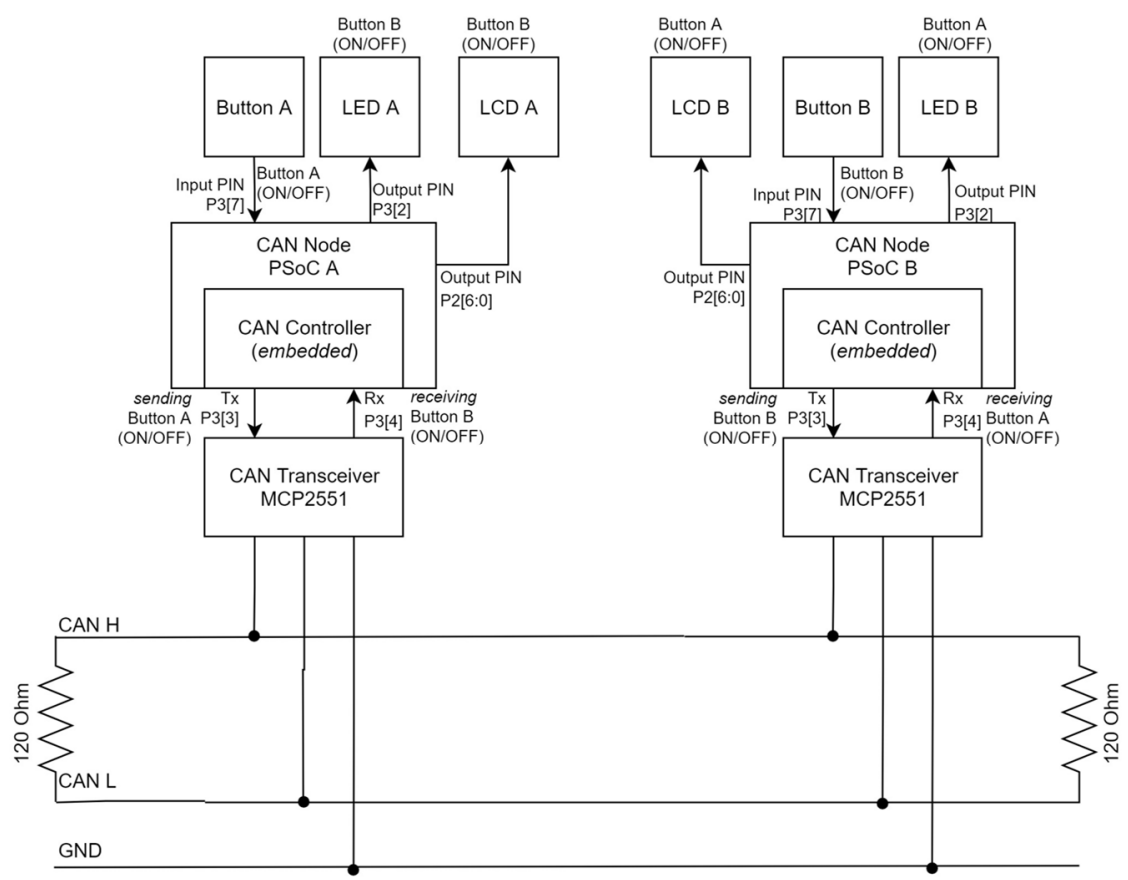

(a)

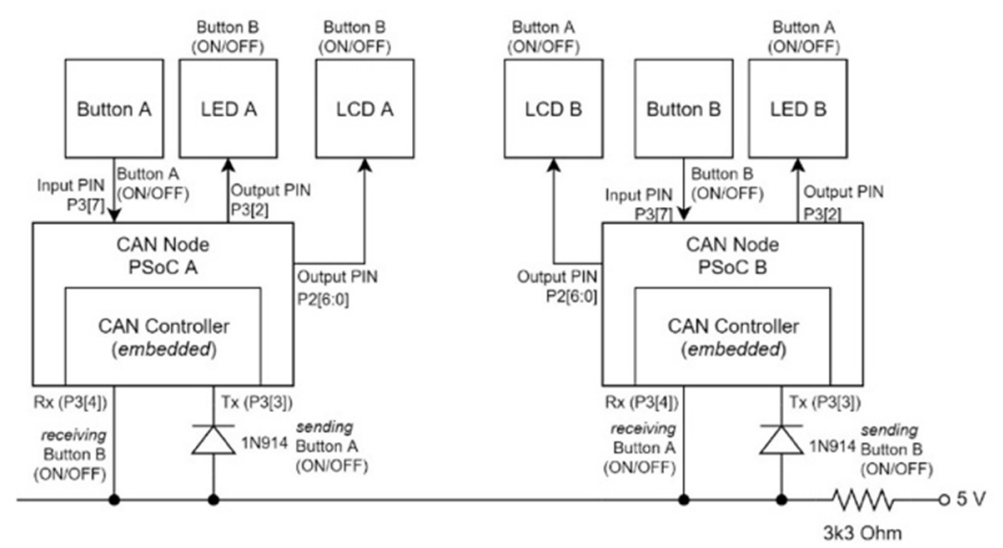

(b)

Gambar 4. Skema implementasi jaringan CAN dengan (a) pemancar-penerima dan (b) tanpa pemancarpenerima [14].

Jenis komunikasi antar node pada program yang dibangun dalam penelitian ini adalah komunikasi full duplex, yang merupakan bentuk komunikasi dua arah, dimana masing-masing node dapat menjalankan fungsi transmisi dan penerimaan data dalam waktu bersamaan. Skema kontrol pada jaringan CAN dengan pemancar-penerima dan tanpa pemancar-penerima yang diimplementasikan pada penelitian ini dapat digambarkan dengan Gambar 4.

Pada masing-masing jaringan terdapat dua CAN node yaitu PSoC A dan PSoC B. Masing-masing PSoC mengirimkan data yang berasal dari perangkat input berupa tombol, yang kemudian akan diterima dan ditampilkan melalui dua perangkat output yaitu LED dan LCD. Tombol yang digunakan bersifat "normally on", sehingga tombol akan bernilai "0" ketika menerima input (ditekan) dan bernilai "1" saat tidak ditekan. Pembacaan dari tombol tersebut kemudian dikirimkan sebagai pesan CAN oleh tiap node. PSoC A akan menerima data "ON/OFF"-nya Tombol B yang dikirimkan oleh PSoC B, yang kemudian data tersebut akan menyalakan LED A dan menampilkan tulisan "LED ON" di LCD A. Sebaliknya, PSoC B akan menerima data 
"ON/OFF"-nya Tombol A yang dikirimkan oleh PSoC A, yang kemudian menyalakan LED B dan menampilkan tulisan pada LCD B.

Jaringan CAN dengan pemancar-penerima merupakan jaringan yang telah umum digunakan, dimana pada penelitian ini digunakan skema jaringan yang memenuhi kebutuhan dari physical layer jenis kecepatan tinggi berstandar ISO 11898 [15][16]. Sesuai spesifikasi pada standar ISO 11898, maka kedua kabel CANH dan CANL dibatasi (terminated) dengan resistor $120 \Omega$ pada kedua ujungnya. Terminasi dengan resistor $120 \Omega$ pada kedua ujung kabel bertujuan untuk mencocokan dengan impedansi karakteristik dari kabel twisted-pair yang digunakan dalam jaringan CAN, sehingga menghindari refleksi sinyal.

Jaringan CAN tanpa pemancar-penerima yang digunakan merupakan single wire, dimana pin receiver (Rx) tersambung pada kabel dengan $\mathrm{VCC}=5 \mathrm{~V}$, melalui sebuah pull-up resistor $3 \mathrm{k} 3 \Omega$. Resistor sebesar $3 \mathrm{k} 3 \Omega$ dipilih agar arus pada pin input tidak melebihi 1,6 mA. Pin pemancar (Tx) terhubung pada kabel melalui sebuah fast diode 1N914 untuk mencegah terjadinya hubung singkat pada pin output.

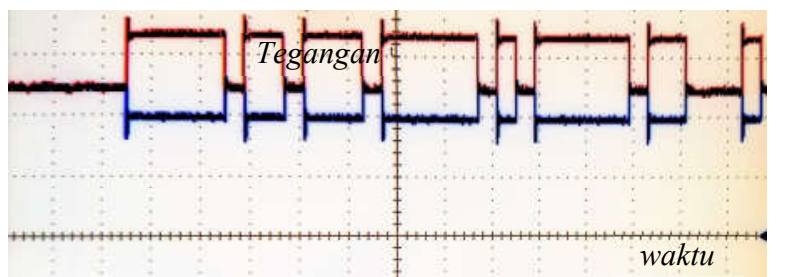

Gambar 5. Sinyal tegangan pada jaringan CAN dengan pemancar penerima (Tegangan/Div $=1 \mathrm{~V}$ dan Waktu/Div $=20 \mu \mathrm{s})$

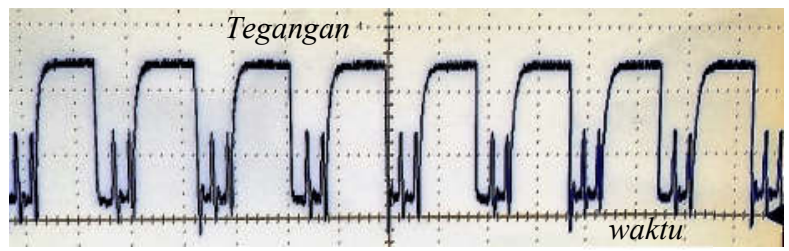

Gambar 6. Sinyal tegangan pada jaringan CAN dengan tanpa pemancar penerima ( $\mathrm{T}$ egangan $/$ Div $=2 \mathrm{~V}$ dan Waktu $/$ Div $=$ $20 \mu \mathrm{s})$

Pada Gambar 5, diamati bentuk sinyal tegangan yang terjadi dalam proses arbitrasi pada saluran $\mathrm{CANH}$ dan CANL jaringan CAN dengan pemancar-penerima. Pada CANH dan CANL, bit resesif "1" direpresentasikan pada tegangan yang sama, yaitu dalam kondisi "floating" pada tegangan 2,5 V. Sesuai dengan spesifikasi ISO 11898, bahwa pada bit dominan "0", differential signal yang terbentuk mempunyai beda tegangan antara $\mathrm{CANH}$ dan CANL sebesar 1,5 V. Gambar6, merupakan single-ended signal, dimana sesuai standar single wire CAN SAE J2411[17] bahwa beda tegangan antara kondisi tinggi dan rendah adalah $4 \mathrm{~V}$.

Untuk membandingkan dan mengevaluasi nilai parameter latensi dari kedua jaringan, maka diselidiki batas perubahan parameter latensi terhadap panjang kabel dari jaringan CAN tanpa pemanca-penerima dengan digunakan variasi panjang kabel sebesar $25 \mathrm{~m}, 30 \mathrm{~m}, 35 \mathrm{~m}, 40 \mathrm{~m}, 45$ $\mathrm{m}, 50 \mathrm{~m}, 55 \mathrm{~m}, 60 \mathrm{~m}, 65 \mathrm{~m}$, dan $70 \mathrm{~m}$.

Setelah melakukan pengambilan data parameter latensi dalam variasi panjang kabel untuk jaringan CAN tanpa pemancar-penerima, diperoleh data nilai parameter latensi yang berubah secara pesat saat panjang kabel $65 \mathrm{~m}$ dan $70 \mathrm{~m}$. Dengan demikian, maka untuk membandingkan dan mengevaluasi kedua jaringan CAN, dilakukan pengambilan data latensi untuk panjang kabel $50 \mathrm{~m}$, $55 \mathrm{~m}, 60 \mathrm{~m}, 65 \mathrm{~m}$, dan $70 \mathrm{~m}$. Hasil pengambilan data latensi pada kedua jaringan CAN terhadap variasi panjang kabel direpresentasikan pada Tabel 3.

Tabel 3 Data latensi dalam ms dari kedua jaringan CAN

\begin{tabular}{c|ccccc}
\hline \multirow{2}{*}{$\begin{array}{c}\text { Jenis Jaringan } \\
\text { CAN }\end{array}$} & $50 \mathrm{~m}$ & $55 \mathrm{~m}$ & $60 \mathrm{~m}$ & $65 \mathrm{~m}$ & $70 \mathrm{~m}$ \\
\cline { 2 - 6 } & 16,0 & 16,0 & 12,8 & 19,2 & 19,2 \\
& 18,0 & 15,6 & 15,6 & 16,8 & 19,6 \\
Pemancar- & 15,2 & 17,6 & 14,4 & 14,0 & 17,2 \\
penerima & 9,6 & 16,4 & 15,2 & 17,2 & 16,0 \\
& 16,8 & 15,2 & 16,0 & 14,4 & 18,4 \\
\hline & 16,0 & 16,8 & 16,8 & 38,4 & 33,6 \\
& 13,6 & 14,8 & 18,4 & 26,8 & 59,2 \\
Tanpa pemancar- & 16,4 & 16,4 & 14,0 & 36,8 & 49,6 \\
penerima & 17,2 & 18,0 & 23,2 & 50,4 & 124,0 \\
& 18,0 & 20,8 & 19,6 & 65,6 & 26,8 \\
\hline
\end{tabular}

\subsection{Analisis Pengaruh Pemancar-penerima dan Pengaruh Panjang Kabel pada Jaringan CAN}

Analisis data dilakukan dengan melakukan uji analisis varians dua arah, dengan signifikasi sebesar $0,05(\alpha=0.05)$ atau tingkat kepercayaan sebesar $95 \%$. Sebelum melakukan uji analisis varians dua arah, asumsi berupa data yang terdistribusi normal 
serta nilai variansi yang homogen harus terpenuhi. Hasil uji normalitas dan uji homogenitas varians menunjukkan bahwa asumsi-asumsi tersebut terpenuhi, sehingga uji analisis varians dua arah dapat dilakukan. Uji analisis varians dua arah untuk data hasil pengukuran berulang yang dilakukan akan menghasilkan tiga buah hasil, yaitu hasil dari pengaruh jenis jaringan CAN dengan/tanpa pemancar-penerima, pengaruh panjang kabel, dan hasil dari interaksi keduanya.

Analisis pengaruh dari jenis jaringan CAN dengan/tanpa pemancar-penerima terhadap latensi dengan menggunakan analisis variansi menghasilkan nilai-p sebesar 0,0003 (Tabel 4). Karena didapatkan nilai tersebut lebih kecil dari $\alpha$, maka hipotesis awal $\left(\mathrm{H}_{0}\right)$ yang menyatakan tidak adanya pengaruh dari jenis jaringan CAN dengan/tanpa pemancar-penerima terhadap latensi ditolak dan menerima hipotesis alternatif $\left(\mathrm{H}_{1}\right)$. Dengan demikian, maka artinya terdapat pengaruh signifikan antara memakai dan tidak memakai pemancar-penerima terhadap nilai parameter latensi.

Tabel 4. Hasil uji analisis variansi dua arah pengaruh jaringan CAN dengan/tanpa pemancar-penerima dan panjang kabel terhadap latensi

\begin{tabular}{cccccc}
\hline & DK & $\begin{array}{c}\text { Jumlah } \\
\text { kuadrat }\end{array}$ & $\begin{array}{c}\text { Rerata } \\
\text { Kuadrat }\end{array}$ & nilai-F & nilai-p \\
\hline $\begin{array}{c}\text { Jaringan } \\
\text { CAN }\end{array}$ & 1 & 2720,3 & 2720,27 & 15,46 & 0,0003 \\
$\begin{array}{c}\text { Panjang } \\
\text { Kabel }\end{array}$ & 4 & 4167,4 & 1041,84 & 5,92 & 0,0008 \\
Interaksi & 4 & 3292,1 & 823,04 & 4,68 & 0,0034 \\
\hline \multicolumn{7}{c}{ Residu } & 40 & 7037,3 & 175,93 & & \\
\hline \multicolumn{7}{l}{ catatan:DK adalah derajat kebebasan } \\
\end{tabular}

Analisis pengaruh panjang kabel dengan menggunakan analisis variansi menghasilkan nilaip lebih kecil dari $\alpha$ yaitu sebesar 0,0008 (Tabel 4), maka hipotesis awal $\left(\mathrm{H}_{0}\right)$ yang menyatakan tidak adanya pengaruh panjang kabel terhadap latensi ditolak dan hipotesis alternatif $\left(\mathrm{H}_{1}\right)$ diterima. Dengan demikian, maka terdapat pengaruh signifikan dari variasi panjang kabel yang dilakukan terhadap nilai parameter latensi.

Interaksi antara jenis jaringan CAN dengan/tanpa pemancar-penerima dan panjang kabel menghasilkan nilai-p lebih kecil dari $\alpha$ yaitu sebesar 0,0034 (Tabel 4), maka hipotesis awal $\left(\mathrm{H}_{0}\right)$ yang menyatakan tidak adanya pengaruh interaksi terhadap latensi ditolak dan menerima hipotesis alternatif $\left(\mathrm{H}_{1}\right)$. Dengan demikian, maka pengaruh dari interaksi tersebut terhadap parameter latensi berbeda secara signifikan.

Berdasarkan uji analisis varians dua arah yang dilakukan, didapatkan bahwa ketiga hasil analisis variansi tersebut menolak $\mathrm{H}_{0}$ dan menerima $\mathrm{H}_{1}$, artinya terdapat perbedaan signifikan dalam kedua pengaruh dan interaksi tersebut. Dengan menggunakan analisis pada box plot dan uji Tukey untuk latensi terhadap panjang kabel pada jaringan CAN tanpa pemancar-penerima, maka akan didapatkan informasi mengenai pada panjang kabel berapa nilai parameter latensi dari kedua jaringan CAN dengan dan tanpa pemancar-penerima berbeda secara signifikan.

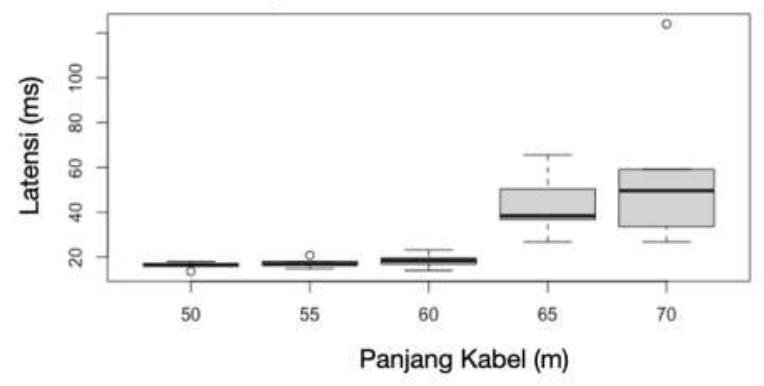

Gambar 5. Box plot latensi terhadap panjang kabel pada jaringan CAN tanpa pemancarpenerima.

Pada box plot latensi terhadap panjang kabel pada jaringan CAN tanpa pemancar-penerima (Gambar 5) terlihat bahwa nilai latensi dari jaringan CAN tanpa pemancar-penerima pada panjang kabel lebih dari $65 \mathrm{~m}$ mempunyai nilai jauh lebih besar dibanding nilai latensi dari jaringan CAN dengan tanpa pemancar-penerima pada panjang kabel kurang dari $65 \mathrm{~m}$. Hasil uji Tukey pada jaringan CAN tanpa pemancar-penerima (Tabel 6) juga menunjukan nilai-p pada latensi pada jaringan CAN tanpa pemancar-penerima tidak berbeda berbeda secara signifikan pada panjang kabel kurang dari $65 \mathrm{~m}$.

Tabel 5. Hasil uji Tukey pada jaringan CAN tanpa pemancar-penerima

\begin{tabular}{ccccc}
\hline $\begin{array}{c}\text { Panjang } \\
\text { Kabel }\end{array}$ & Beda & Bawah & Atas & Nilai-p \\
\hline $55-50$ & 1,12 & $-34,18$ & 36,42 & 0,9999 \\
$60-50$ & 2,16 & $-33,14$ & 37,46 & 0,9997 \\
$65-50$ & 27,36 & $-7,94$ & 62,66 & 0,1799 \\
$70-50$ & 42,40 & 7,10 & 77,70 & 0,0139 \\
$60-55$ & 1,04 & $-34,26$ & 36,34 & 0,9999 \\
$65-55$ & 26,24 & $-9,06$ & 61,54 & 0,2113 \\
$70-55$ & 41,28 & 5,98 & 76,58 & 0,0171 \\
$65-60$ & 25,20 & $-10,10$ & 60,50 & 0,2441 \\
$70-60$ & 40,24 & 4,94 & 75,54 & 0,0207 \\
$70-65$ & 15,04 & $-20,26$ & 50,34 & 0,7088 \\
\hline
\end{tabular}




\section{Kesimpulan}

Berdasarkan hasil analisis data melalui uji analisis variansi dua jalur, dapat disimpulkan bahwa digunakan atau tidaknya pemancarpenerima pada jaringan CAN, serta variasi nilai panjang kabel yang memisahkan dua CAN node dalam melakukan komunikasi, memberikan pengaruh signifikan terhadap latensi. Dengan menggunakan uji Tukey juga didapatkan hasil bahwa selama panjang kabel kurang dari $65 \mathrm{~m}$, nilai parameter latensi dari jaringan CAN tanpa pemancar-penerima tidak berbeda secara signifikan. Dengan demikian, maka didapatkan kesimpulan bahwa jaringan CAN tanpa pemancar-penerima dapat digunakan dengan baik selama panjang kabel kurang dari $65 \mathrm{~m}$.

\section{Daftar Pustaka}

[1] A. S. Shinde, A. S. Deshpande, P. Kalamkar, A. R. Nichal, "Implementation of CAN Bus Protocol", International Journal on Recent and Innovation Trends in Computing and Communication. vol. 2, no. 6, pp.. 1568-1573, 2014.

[2] S. Corrigan, Introduction to the Controller Area Network (CAN). Texas Instruments. Application Report: SLOA101B. 2016.

[3] H. F Othman., Y. R. Aji, F. T Fakhreddin., A. R Al-Ali, "Controller Area Networks: Evolution and Applications". in Proceeding of 2nd Information and Communication Technologies, vol. 2, pp. 3088-3093, 2006.

[4] H. Chen, "Research on the Controller Area Network", in. Proceeding of International Conference on Networking and Digital Society, pp. 251-254, 2009.

[5] J. Barrenscheen, On-Board Communication via CAN without Transceiver. Siemens. Application Note: AP2921.

[6] R. Boys.. CAN Primer: Creating Your Own Network. Keil. 2012.

[7] M. Ranjith, Getting Started with Controller Area Network (CAN). Cypress Semiconductor. Application Note: AN52701. 2017

[8] Datsheet Digital Storage OsciloscopeDSO5000P Series, Hantek, 2018.

[9] J. M. Horgan, "Probability with $R$ : an introduction with computer science applications, "John Wiley \& Sons, 2019

[10] CAN Bus Data Cables: Delivering Signal \& Supplying Power for Transportation
Applications. General Cable Technologies Corporation. 2015.

[11] Electrical Properties of Plastic Materials. Professional Plastics Inc, 2011.

[12] American Wire Gauge (AWG) Conductor Size Table. Solaris, 2007

[13] M. Reta-Hernandez. "Transmission Line Parameters". pada: Grigsby L. L. Editors. Electric Power Generation, Transmission, and Distribution. 2nd ed. Boca Raton: Taylor \& Francis. 2006.

[14] R. M. A. B. Satria, Analisis Parameter Latency pada Jaringan berbasis CAN Bus dengan Transceiver dan Tanpa Transceiver. Tugas Akhir. Yogyakarta, Universitas Gadjah Mada; 2018.

[15] S. Corrigan, Controller Area Network Physical Layer Requirements. Texas Instruments. Application Report: SLLA270. 2008.

[16] P. A. Richards, CAN Physical Layer Discussion. Microchip Technology Inc. Application Note: AN228. 2002.

[17] Single Wire CAN Network for Vehicle Applications, SAE J2411, 2000

\section{Biodata Penulis}

R. Mochammad A. B. Satria, menempuh studi sarjana pada program studi Teknik Fisika, Universitas Gadjah Mada. Bidang riset yang diminati mencakup instrumentasi dan kontrol.

Awang N. I. Wardana, mendapat gelar Doktor di Universität Kassel. Saat ini berprofesi sebagai dosen di Departemen Teknik Nuklir dan Teknik Fisika, Universitas Gadjah Mada, Yogyakarta. Bidang riset yang ditekuni adalah otomasi proses, pengembangan sistem, dan sistem terintegrasi.

Nazrul Effendy, mendapat gelar Doktor di Chulalongkorn University. Saat ini berprofesi sebagai dosen di Departemen Teknik Nuklir dan Teknik Fisika, Universitas Gadjah Mada, Yogyakarta. Bidang riset yang ditekuni adalah instrumentasi dan kontrol, kecerdasan buatan, dan pemrosesan sinyal. 